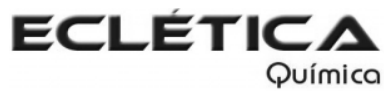

www.scielo.br/eq

www.ecletica.iq.unesp.br

Volume 33, número 4, 2008

\title{
Inhibitors of Clostridium histolyticum colagenase
}

\author{
S. R. A. Leite* \\ Instituto de Química, UNESP, CP 355, 14801-970, Araraquara, SP, Brasil \\ *leite@iq.unesp.br
}

\begin{abstract}
Different substances were tested as inhibitors of Clostridium histolyticum collagenase, both experimental and theoretically. The in vitro collagenase activity, alone and in the presence of inhibitors, was quantified by reaction with bovine collagen and dosage of the releasing amino acids. Collagenaseinhibitor interaction was studied theoretically by docking computational calculations. Only one among the tested substances showed inhibitor activity against the bacterial collagenase.
\end{abstract}

Keywords: Clostridium histolyticum; collagenase; inhibitors; docking.

\section{Introduction}

The gas gangrene or myonecrosis is a serious infectious process of fast evolution, that may arises from the contamination of wounds for its etiological agents. Although the disease is known since remote times, its etiology was only defined in the end of the XIX century, when Gram-positive bacilli obligate anaerobes were isolated from infected wounds. Initially classified under the gender Bacillus, were later included in the gender Clostridium. Although the species Clostridium perfringens is more frequently isolated from gas gangrene lesions, other Clostridium species also occur as its etiological agents, like $C$. histolyticum, C. septicum, $C$. sporogenes and $C$. bifermentans. These organisms, under appropriate conditions, namely, low partial tension of oxygen, multiply quickly and produce a series of toxins and hydrolytic enzymes, responsible for the pathogeny and clinical manifestations of the process. This it is characterized by extensive necrosis of the muscular and conjunctive tissues starting in the neighborhoods of the infected wound, and by systemic manifestations, that increase with the development of the process. The primary cause of the necrosis is the lysis of the tissue structures by lytic enzymes, e.g., lecitinase, hyaluronidase, desoxi-ribonuclease and several proteases, as gelatinase and collagenase, with prominence for this last one, as one of the main responsible for the destruction of conjunctive, muscular and vascular tissues. This collagenase is obtained commercially from cultures of Clostridium histolyticum. This is the enzyme with collagenolitic activity more used in practice, for example, in the separation of cells and in dermatological products.

In the present work we intended to study inhibitors of the collagenase of $C$. histolyticum. Inhibitors of this enzyme should be used as auxiliary drugs for treatment of gas gangrene. The work consisted of an experimental part, in which the effect of different substances was verified on collagenase of $C$. histolyticum, and of a theoretical part, in which the simulation of the structures of these substances and their interaction with the collagenase were performed. 


\section{Experimental}

The collagenase activity was measured by collagen hydrolysis and determination of the released amino acids. The method was adapted from Mandl et al [1], in which native collagen is incubated for 5 hours with collagenase and the amino acids are colorimetrically determined by reaction with ninhydrine [2]. The reaction medium was buffered to $\mathrm{pH} 7,5$ with Tricine $50 \mathrm{mM}$ added of $0,4 \mathrm{M} \mathrm{NaCl}$. For the inhibition trials, the ligands were mixed to the enzyme one hour before the beginning of the reaction.

The choice of substances for test was made in function of reports in the literature (experimental or clinical) among common drugs with inhibiting effect upon collagenases. The selected drugs have different structures and pharmacological activities, but all share such inhibiting effect [3-9]. Six ligands were tested: three oxicans, namely Meloxicam, Tenoxicam and Piroxicam, tetracycline, doxycycline and sodium alendronate. The inhibition constant was determined for those that exhibited activity against the enzyme.

C. histolyticum collagenase (type IA) was obtained from Sigma, St. Louis, MO, USA. The drugs (ligands) were bought from Purifarma, São Paulo, SP, Brazil. The bovine collagen was produced by Gelita South America, Maringá, PR, Brazil.

The computational calculations comprise the determination of the three-dimensional structure of the ligands by energy minimization methods, and the simulation of the interaction between ligands and collagenase active site by a docking procedure. The enzyme structure was obtained from Protein Data Bank (structure 1NQD), determined by X-ray diffraction. The structures of the collagen co-crystallized with any inhibitor are not known. Therefore the area of the surface of the enzyme capable to interact with ligands had to be obtained by simulation. For this purpose, a model of a fragment of collagen, constituted by the hexapeptide pro-pro-gly-pro-pro-gly, was positioned close to active center amino acids residues and then performed a grid calculation [10].

Docking calculation and a mixed Quantum-Classical Mechanics determination of ligand-enzyme interaction energy, led to the most probable complex structures $[10,11]$.
Calculations were performed on a Compaq AP400 workstation with two processors (Windows software for Classical and Quantum Mechanics energy minimization) and on a Silicon Graphics Octane workstation (Unix software for docking and $a b$ initio Quantum Mechanics calculation). For the former it was used CAChe Worksystem 5.04 for Windows (Fujitsu Systems Business of America, Inc., Beaverton, OR, USA) [12] and for the last First Discovery 1.8 (modules: Glide; Liaison; QSite; Impact) and Jaguar 4.1. for Irix (in other words, SGI Unix) (Schrödinger Inc., Portland, OR, USA).[10, 11]

\section{Results and Discussion}

The kinetic parameters for the collagenase-catalyzed hydrolysis of bovine collagen were determined from the plot of absorbance of ninhydrine-amino acid reaction product versus collagen concentration in $\mathrm{mol} / \mathrm{l}$, considering the protein molecular weight as $3,00 \times 10^{5} \mathrm{D}$. This system displays a standard Michaelis-Menten kinetics with a $\mathrm{V}=1,45 \mu \mathrm{kat}$ and $\mathrm{Km}=19,9 \mu \mathrm{M}$. The specific activity results equal to $363 \mathrm{~kat} / \mathrm{kg}$.

Only Piroxicam inhibited the bacterial collagenase among all the tested drugs (Fig. 4). The others had no significant effect (including the remaining oxicans, fig. 1 , doxycycline, fig. 2 , and tetracycline, fig. 3), except alendronate that increased enzyme activity (Fig. 5).

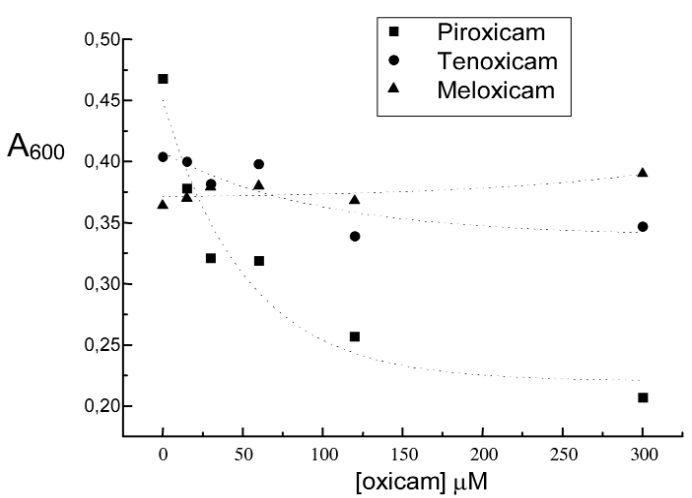

Figure 1. Effect of oxicans upon activity of $C$. histolyticum collagenase, measured by absorbance at $600 \mathrm{~nm}$ of the ninhydrine-amino acid reaction product. 


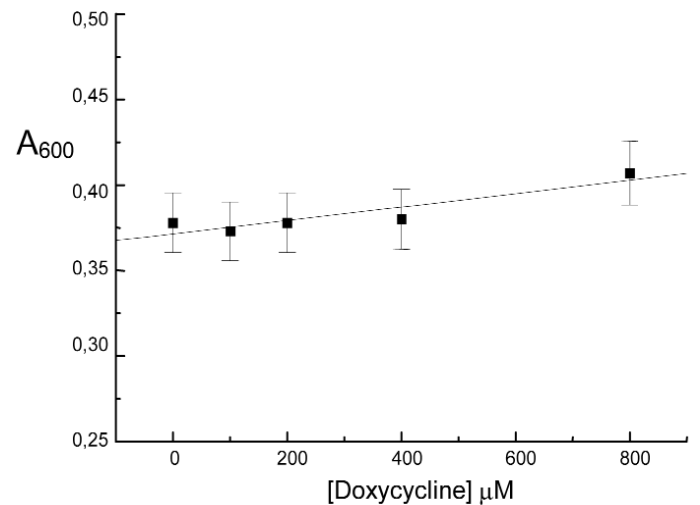

Figure 2. Effect of doxycycline upon activity of $C$. histolyticum collagenase.

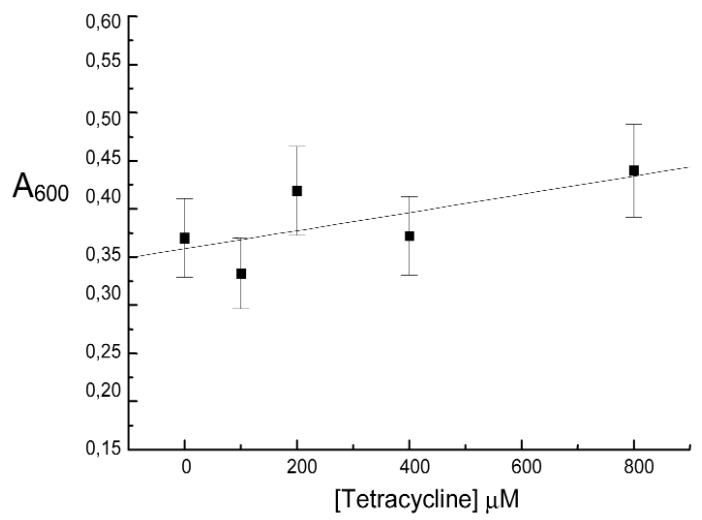

Figure 3. Effect of tetracycline upon activity of $C$. histolyticum collagenase.

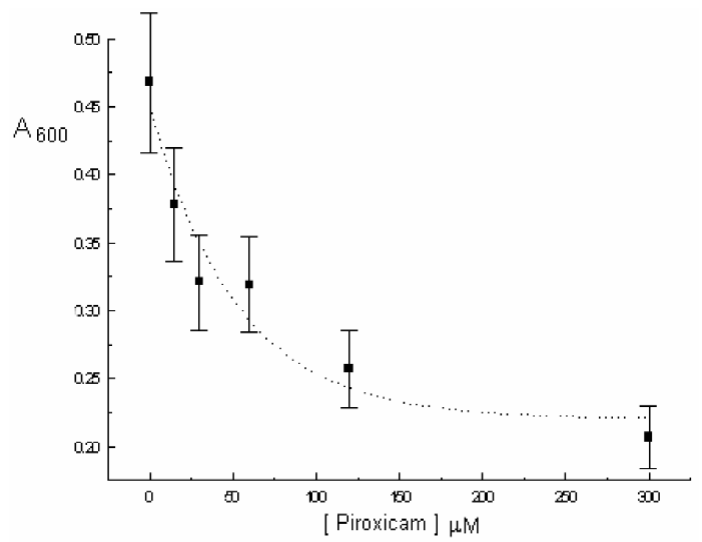

Figure 4. Effect of Piroxicam upon activity of $C$. histolyticum collagenase, measured by absorbance at $600 \mathrm{~nm}$ of the ninhydrine-amino acid reaction product. IC50 $=2,2 \times 10^{-4} \mathrm{~mol} / 1$.
The constant of inhibition Ki of the system Piroxicam-collagenase (constant of enzymeinhibitor dissociation) was calculated starting from the Michaelis-Menten graph, namely:

$$
\begin{gathered}
\mathrm{Km}_{\mathrm{a}}=6,81 \mathrm{mg} / \mathrm{ml}=22,7 \mu \mathrm{M} \\
\mathrm{V}=1,07 \Delta \mathrm{A} / 5 \mathrm{~h} \text { or } 1,37 \mu \mathrm{kat}
\end{gathered}
$$

Where $\mathrm{Km}_{\mathrm{a}}$ is the Apparent Michaelis Constant. Then:

$\mathrm{Ki}=\mathrm{Km}[\mathrm{I}] / \mathrm{Km}_{\mathrm{a}}-\mathrm{Km}$, where $[\mathrm{I}]$ is the inhibitor concentration, [Piroxicam]. Therefore,

$$
\mathrm{Ki}=1,42 \mathrm{mM}
$$

The maximum reaction speed measured in presence of Piroxicam was the same of the reaction without inhibitor, within the experimental uncertainty, what confirms the competitive nature of the process. The apparent Michaelis constant has a value only $14 \%$ greater of the true one, what implies in a relatively high $\mathrm{Ki}(1,42$ $\mathrm{mM}$ ), indicating a weak inhibitor - enzyme affinity. In other words, Piroxicam is a poor candidate for a drug as a bacterial collagenase inhibitor. However, maybe a good starting point to search more active derivates.

As stated above, the others ligands did not inhibit the collagenase of $C$. histolyticum. Curiously, the alendronate increased enzyme activity (fig. 5).

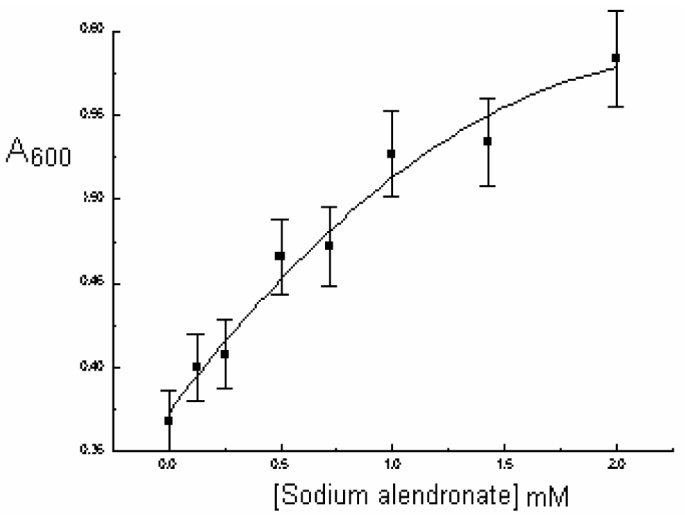

Figure 5. Effect of alendronate upon activity of $C$. histolyticum collagenase, measured by absorbance at $600 \mathrm{~nm}$ of the amino-amino acid product reaction. 
Docking calculations defined the best geometry for ligand-enzyme interaction. The best poses between each ligand and collagenase active site were select. See figure 6 as an example. Tetracycline was the only ligand for which a favorable interaction with the enzyme was not gotten. The calculation didn't supply any adjustment of the tetracycline with the active site that resulted in attractive interactions among their structures.

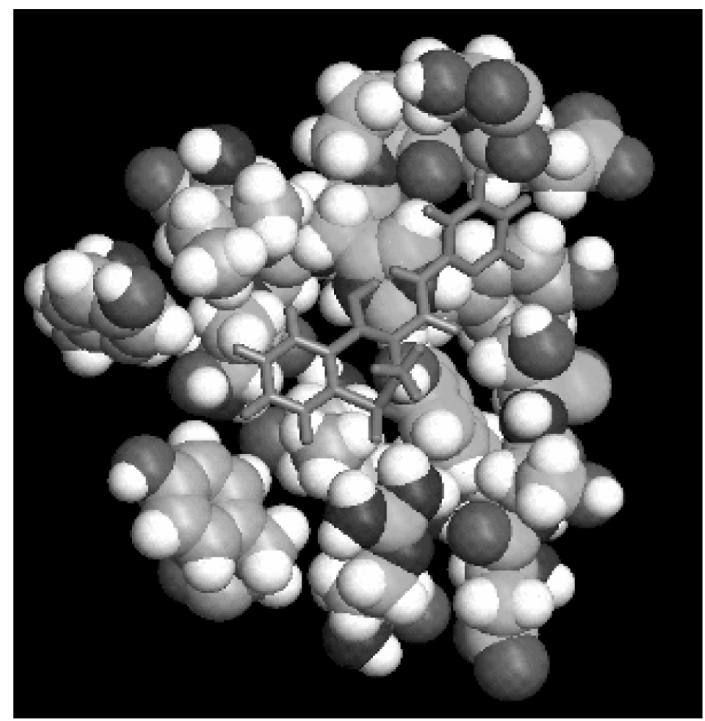

Figure 6. Piroxicam bonding to C. histolyticum collagenase active site.

The best geometries obtained through the docking calculation represent the low interaction energy between ligand-enzyme, resulting in stronger chemical bonds. Among them stand out hydrogen bonds, whose involvement of groups of enzyme active site can explain the effect on the enzymatic activity. The number and the position of hydrogen bonds formed between ligand and enzyme are described in the table 1.

All the best poses obtained in the "docking" procedure were submitted to energy calculation. This calculation was mixed: $a b$ initio Quantum Mechanics, which is more accurate, for the ligand and the neighboring area of the enzyme, and Classic Molecular Mechanics for the rest of the protein, because is unviable to per-
Table 1. Hydrogen bonds between ligands and active site of Clostridium histolyticum collagenase.

\begin{tabular}{lccccc}
\hline Ligands & $\begin{array}{c}\text { Number of hydrogen bonds formed } \\
\text { with each amino acid residue }\end{array}$ \\
\hline Arg 929 & Tyr 931 & Thr 957 & His 959 Asp 966 \\
Meloxicam & 3 & - & 1 & - & - \\
Tenoxicam & 1 & 1 & - & - & - \\
Piroxicam & 3 & 1 & - & 1 & - \\
Alendronate & 2 & 1 & - & - & - \\
Doxycycline & 2 & - & - & - & 1 \\
\hline
\end{tabular}

form an ab initio Quantum Mechanics method with a too many atoms system like a protein. The energy of the isolated ligand was obtained by the same Quantum Mechanics method and of the free enzyme by analogous mixed procedure. Classic Molecular Mechanics utilized OPLS-AA force field, and the $a b$ initio Quantum Mechanics calculation used a density functional theory type B3LYP with a base lacvp+. Starting from these results the total ligand-enzyme bond energies were calculated, namely:

$$
\mathrm{E}_{\mathrm{b}}=\mathrm{E}_{1}+\mathrm{E}_{\mathrm{e}}-\mathrm{E}_{\mathrm{cle}}
$$

Where: $\mathrm{E}_{\mathrm{b}}$ bond energy, $\mathrm{E}_{1}$ energy of ligand, $\mathrm{E}_{\mathrm{e}}$ energy of enzyme, $E_{\text {cle }}$ energy of complex ligandenzyme. See Table 2 for the results.

Table 2. Total bond energy between ligands and collagenase of Clostridium histolyticum.

\begin{tabular}{ll}
\hline Ligands & $\begin{array}{l}\text { Bond energy enzyme-lig- } \\
\text { and (hartree) }\end{array}$ \\
\hline Meloxicam & $-0,186001$ \\
Tenoxicam & $-0,200768$ \\
Piroxicam & $-0,210681$ \\
Alendronate & $-0,428059$ \\
Doxycycline & $-0,189599$ \\
\hline
\end{tabular}

Bigger bond energy means a stronger interaction between ligand and enzyme, but does not mean that this ligand is a better inhibitor, because this property depends on the nature of the interaction and the groups involved. Outstanding example in this group is alen- 
dronate: the worst inhibitor (actually an activator) is the molecule that interacts more strongly with the enzyme. On the other hand, when similar molecules are compared, as the oxicans, we see that Piroxicam is the best inhibitor and the more strongly bonding to the enzyme. The conclusion is: first it is necessary to find the species that interact more favorably regarding the expected effect. Once found a substance like this, its structure must be modified seeking to obtain a stronger interaction that intensifies such effect. The definition of which interactions are favorable to the inhibiting effect depends on the knowledge of which groups of the active site are important for the enzymatic activity. In the case of Clostridium histolyticum collagenase, Wilson et al. [13] identified the amino acids residues relevant for the enzymatic activity, through the analysis of the mutagenesis effect of each residue upon such activity. The authors concluded that:

1. Thr957, Tyr970, Leu992, Tyr994 e Tyr996 amino acids residues are very important for the bond with collagen (Tyr994 is probably the most important: its substitution reduces the activity in more than 5 times).

2. Tyr990, Tyr931, Tyr932, Asp966 e Asp974 are less important, because their loss or blockade have a small inhibition effect.

3. His959 interacts with only one of the four collagen orientations proposed by the authors.

4. Arg929 mutation intensifies the bonding with collagen.

Based on these conclusions, we can discuss the experimental results regarding docking calculations.

Initially consider the oxicans series: Piroxicam, Tenoxicam and Meloxicam. The experiments show that the inhibiting effect on bacterial collagenase decreases from Piroxicam to Meloxicam. According to Table 2, total interaction energy follows the exact sequence above: the more negative figure (stronger global interaction) is that of Piroxicam, following by Tenoxicam and Meloxicam bond energies. Concerning the amino acids residues that interact with the oxicans, first, the Piroxicam, although it forms three hydrogen bonds with $\operatorname{Arg} 929$, whose blockade is activator, it is the only of the oxicans tested that bonds to two groups of relevance for the interaction enzyme-substratum, what should generate a more efficient blockade to the approach and interaction of the enzyme with collagen. Tenoxicam and Meloxicam bond to Arg929 too and each one to a second relevant group for enzyme activity: Tyr931 with Tenoxicam and Thr957 with Meloxicam. However, Meloxicam bonds much more strongly to Arg929 (three hydrogen bonds) than Tenoxicam (only one), residue whose blockade is stimulating for the activity, what can explain the complete absence of inhibiting effect in the case of Meloxicam.

Concerning the tested tetracyclines, it was possible to simulate the docking only with the doxycycline, because the calculation with tetracycline did not result in any favorable interaction. The calculated bond energy for doxycycline-enzyme is similar to that of Meloxicamenzyme (Table 2). The hydrogen bonds between each ligand and the collagenase have much in common, namely, both bond to Arg929, residue whose blockade is activator for the enzyme, Meloxicam by three hydrogen bonds and doxycycline through two. On the other side, both bond to one residue whose blockade is inhibitor: Thr957 for Meloxicam and Asp966 for doxycycline. The former has a more intense influence upon the inhibition of the enzyme than the second, what should compensate the stronger interaction of Meloxicam with Arg929 and to result in a similar effect comparatively to doxycycline.

Finally, Alendronate forms two hydrogen bonds with Arg929 and one with Tyr931, residue whose suppression has very little inhibiting effect. Probably the strong bond energy Alendronate-collagenase translates a very strong interaction between this ligand and Arg929, resulting in the stimulating effect upon enzyme activity of this drug.

\section{Conclusion}

Among the tested compounds, Piroxicam is the only useful as leader for the synthesis of derivates in the search of $C$. histolyticum collagenase inhibitors with larger activity. 
Pay attention that, the calculations for steric adjustment and bond formation between ligands and enzyme active center ("docking") and to obtain bond energies values are very useful in the interpretation of the experimental results. But, as every method of computational simulation, they have their limitations and their results should be considered with caution. They must be considered as an aid for interpretation of the experiences and for planning news ones, but not as their substitutes.

\section{Acknowledgements}

The author is grateful to Fundação de Amparo à Pesquisa do Estado de São Paulo (FAPESP) for financial support.

Received May 282008

Accepted September 162008

S. R. A. Leite. Inibidores da colagenase do Clostridium histolyticum

Resumo: Diferentes substâncias foram testadas como inibidores da colagenase do Clostridium histolyticum, dos pontos de vista experimental e teórico. A atividade da colagenase, isolada e na presença das substâncias testadas, foi medida através da reação de hidrólise do colágeno bovino e dosagem dos aminoácidos liberados. A interação inibidor-enzima foi estudada teoricamente, mediante simulação computacional de ancoragem. Das substâncias testadas, somente uma apresentou atividade inibidora sobre a colagenase bacteriana.

Palavras-chave: Clostridium histolyticum, colagenase, inibidores, interação enzima-ligante.

\section{References}

[1] I. Mandl, J. MacLennan, E. Howes, R. DeBellis and A. Sohler, J Clin Invest 32 (1953) 1323-1329.

[2] S. Moore and W. H. Stein, J Biol Chem 211 (1954) 907-913.

[3] A.Barracchini, N.Franceschini, G.Minisola,

G.C.Pantaleoni, A.Di Giulio, A.Oratore, G.Amicosante, 1999.

Meloxicam and Indometacin activity on human matrix metalloproteinases in synovial fluid. In: Greenwald,R.A., Zucker,S., Golub,L.M. (Eds.), Inhibition of matrix metalloproteinases: therapeutic applications. New York Academy of Sciences, New York, pp. 665-666.

[4] L. M. Golub, M. Wolff and H. M. Lee, J. Periodont. Res. 20 (1985) 12-23.

[5] L. M. Golub, S. Ciancio, N. S. Ramamurthy, M. Leung and T. F. McNamara, J. Periodont. Res. 26 (1990) 321-330. [6] L. M. Golub, T. Sorsa, H. M. Lee, S. Ciancio, D. Sorbi, N. S. Ramamurthy, B. Gruber, T. Salo and Y. T. Konttinen, J. Clin. Periodont. 22 (1995) 100-109.

[7] L.M.Golub, N.S.Ramamurthy, A.Llavaneras, M.E.Ryan, H.M.Lee, Y.Liu, S.Bain, T.Sorsa, 1999. A chemically modified nonantimicrobial tetracycline (CMT-8) inhibits gingival matrix metalloproteinases, periodontal breakdown, and extraoral bone loss in ovariectomized rats. In: Greenwald,R.A., Zucker,S., Golub,L.M. (Eds.), Inhibition of matrix metalloproteinases: therapeutic applications. New York Academy of Sciences, New York, pp. 290-310.

[8] R. A. Greenwald, L. M. Golub, N. S. Ramamurthy, M. Chowdhury, S. A. Moak and T. Sorsa, Bone 22 (1998) 33-38. [9] O.Teronen, P.Heikkila, Y.Konttinen, M.Laitinen, T.Salo, R.Hanemaaijer, A.Teronen, T.Sorsa, 1999. MMP inhibition ad downregulation by biphosphonates. In: Greenwald,R.A., Zucker,S., Golub,L.M. (Eds.), Inhibition of matrix metalloproteinases: therapeutic applications. New York Academy of Sciences, New York, pp. 453-465.

[10] I. Schrödinger, First Discovery: Technical notes for version 1.8. Schrödinger, Inc., Portland, OR, 2001.

[11] I. Schrödinger, Jaguar User's Guide. Version 4.1

Schrödinger, Inc., Portland, OR, 2001.

[12] I. Fujitsu, CAChe 5.0 for Windows User Guide Fujitsu Systems Business of America, Inc., 2001.

[13] J. J. Wilson, O. Matsushita, A. Okabe and J. Sakon, The EMBO Journal 22 (2003) 1743-1752. 